\title{
Disagreement Between Theoretical and Actual Phorcides Outcomes: Is Phorcides Inferior to Treating on the Manifest Refraction? [Letter]
}

This article was published in the following Dove Press journal: Clinical Ophthalmology

\author{
Avi Wallerstein $\mathbb{1}^{1,2, *}$ \\ Mathieu Gauvin ${ }^{1,2, *}$ \\ 'Department of Ophthalmology and \\ Visual Sciences, McGill University, \\ Montreal, QC, Canada; ${ }^{2}$ Department of \\ Research \& Development, LASIK MD, \\ Montreal, QC, Canada \\ *These authors contributed equally to \\ this work
}

\section{Dear Editor}

We read with interest "Topography-Guided Refractive Astigmatism Outcomes: Predictions Comparing Three Different Programming Methods." ${ }^{11}$ In the Manifest group, the calculated theoretical outcomes revealed an unexpectedly elevated postoperative refractive astigmatism average error of $0.56 \pm 0.22 \mathrm{D} .{ }^{1}$ This large amount of theoretical postoperative cylinder was not replicated in a recent real-world clinical study by the same authors, comparing actual topography-guided LASIK outcomes in Phorcides versus manifest-treated eyes. ${ }^{2}$ The reported empirical postoperative astigmatism error average in the Manifest group was as low as $0.15 \mathrm{D}$, fourfold better than that reported in the current theoretical outcomes study. ${ }^{1}$

In the current theoretical study, ${ }^{1}$ only $56 \%$ of Manifest eyes showed a refractive astigmatism error of $0.50 \mathrm{D}$ or less, compared to $96 \%$ of eyes in the real-world clinical study. ${ }^{2}$ In addition, $15 \%$ of Manifest eyes exhibited an "outlier" postoperative refractive astigmatism error of $1.00 \mathrm{D}$ or greater, compared to only $1 \%$ in the real-world study. ${ }^{2}$

The real-world clinical study further revealed that the refractive astigmatism accuracy was statistically inferior in Phorcides eyes that were matched to the FDA study criteria. ${ }^{2}$ Surprisingly, this inferior postoperative SEQ and refractive astigmatism accuracy with Phorcides was accompanied with a significantly better rate of postoperative 20/16 UDVA. ${ }^{2}$ This clinical finding of having superior visual acuity despite inferior refractive accuracy is atypical and inconsistent with current laser vision correction literature. ${ }^{3}$

These conflicting results highlight that the current theoretical outcomes study ${ }^{1}$ does not reflect real-world manifest-treated eyes outcomes, where manifest eyes are superior to Phorcides eyes in terms of refractive astigmatism and SEQ accuracy. ${ }^{2}$ What could explain the significant disagreement between these poor theoretical ${ }^{1}$ versus excellent real-world ${ }^{2}$ manifest-treatment outcomes?

In the theoretical study, vector analyses of postoperative cylindrical errors and programmed cylindrical laser treatment values were used to calculate expected outcomes that in theory may have been obtained using either Manifest, LYRA or Phorcides treatment. Using this methodology, a successful plano postoperative eye treated using the Contoura-measured anterior corneal astigmatism (LYRA protocol) with $1.00 \mathrm{D}$ of difference between manifest and topographical cylinder
Correspondence: Avi Wallerstein MD Level, I 250 Rene-Levesque Blvd W, Montreal, QC H3B 4W8, Canada Tel + | 5/4-908-9888 Ext 2273

Email awallerstein@lasikmd.com 
preoperatively, leads to a theoretical postoperative refractive astigmatism error of $1.00 \mathrm{D}$ in the Manifest group. Such theoretical assumptions are invalid, since published clinical outcomes studies do not necessarily reveal differences in postoperative refractive astigmatism errors between treating the manifest astigmatism, the topographical astigmatism, or the vector planning approach. ${ }^{2,4,5}$

Given that most eyes $(\sim 75 \%)$ were treated using the LYRA protocol prior to such theoretical calculations, and since the preoperative difference between refractive and anterior corneal astigmatism was large, with $73 \%$ of eyes having a difference greater than $0.50 \mathrm{D},{ }^{1}$ the Manifest group was significantly disadvantaged by the study design. This treatment bias, where most eyes were treated using the LYRA protocol and not the manifest, led to an overestimated theoretical refractive astigmatism error in the Manifest group. This explains why the real-word clinical study outcomes do not reflect the current theoretical study outcomes.

In summary, the authors' statement that Phorcides and LYRA "will produce outcomes that are superior to those obtained when the Manifest refraction is entered as the treatment" is scientifically flawed considering: the bias related to treatment type being mostly LYRA, the selection bias introduced from doctors choosing treatment type with undetermined criteria and nomograms, and the same author real-world outcomes study showing superior refractive accuracy outcomes in Manifest eyes compared to Phorcides eyes. A review of over 150,000 of our topography-guided treated eyes, where accurate manifest refraction data and an advanced big data nomogram were used, demonstrates that refractive outcomes of manifesttreated eyes are better than Phorcides, ${ }^{3}$ and LYRA. ${ }^{5}$

\section{Disclosure}

The authors have no conflict to disclose and no financial interest in the subject matter or materials presented herein in this letter to editor. The authors equally contributed to this letter.

\section{References}

1. Stulting RD, Durrie DS, Potvin RJ, et al. Topography-guided refractive astigmatism outcomes: predictions comparing three different programming methods. Clin Ophthalmol. 2020;14:1091-1100. doi:10.21 47/OPTH.S244079

2. Lobanoff M, Stonecipher K, Tooma T, Wexler S, Potvin R. Clinical outcomes after topography-guided LASIK: comparing results based on a new topography analysis algorithm to those based on the manifest refraction. J Cataract Refract Surg. 2020. doi:10.1097/j.jcrs.000 0000000000176

3. Wallerstein A, Gauvin M. Is phorcides more likely to give better vision than treating the manifest refraction? J Cataract Refract Surg. 2020;46 (10): 1451-1452.

4. Arbelaez MC, Alpins N, Verma S, Stamatelatos G, Arbelaez JG, ArbaMosquera S. Clinical outcomes of laser in situ keratomileusis with an aberration-neutral profile centered on the corneal vertex comparing vector planning with manifest refraction planning for the treatment of myopic astigmatism. J Cataract Refract Surg. 2017;43 (12):1504-1514. doi:10.1016/j.jcrs.2017.07.039

5. Wallerstein A, Gauvin M, Qi SR, Bashour M, Cohen M. Primary topography-guided LASIK: treating manifest refractive astigmatism versus topography-measured anterior corneal astigmatism. $J$ Refract Surg. 2019;35:15-23. doi:10.3928/1081597X-20181113-01

\section{Publish your work in this journal}

Clinical Ophthalmology is an international, peer-reviewed journal covering all subspecialties within ophthalmology. Key topics include: Optometry; Visual science; Pharmacology and drug therapy in eye diseases; Basic Sciences; Primary and Secondary eye care; Patient Safety and Quality of Care Improvements. This journal is indexed on PubMed
Central and CAS, and is the official journal of The Society of Clinical Ophthalmology (SCO). The manuscript management system is completely online and includes a very quick and fair peer-review system, which is all easy to use. Visit http://www.dovepress.com/ testimonials.php to read real quotes from published authors. 